\title{
The Effects of an Evidence-based Nursing Training Workshop on Critical Care Nurses' Self-efficacy: A Two-group Pre-test-post-test Quasi-experimental Study
}

\author{
Research Article
}

\author{
Kobra Esfandani ${ }^{1}$, Zeynab Abolhasani ${ }^{2}$, Ali Bahramifar ${ }^{3}$ \\ Saeedeh Memare ${ }^{4}$, Hossein Mrdanparvar ${ }^{5}$, Abolfazl Rahimi ${ }^{6,7^{*}}$
}

1. Master student of critical care Nursing, Iran, Tehran, AJA University of Medical Sciences, Faculty of Nursing

2. MSc of nursing, Nursing faculty, Guilan University of Medical Sciences, Rasht, Iran

3. Anesthesiology, Trauma Research Center, School of Medicine,

Baqiyatallah University of Medical Sciences, Tehran, Islamic Republic of Iran

4. $\mathrm{PhD}$ in Nursing, Assistant Professor, Iran, Tehran, Tehran University of Medical Sciences, Faculty of Nursing, Nursing Management

5. Master student of critical care Nursing, Iran, Esfehan, Esfehan University of Medical Sciences. Faculty of Nursing 6. PhD Assistant Professor, Health Research Center, Nursing Faculty, Baqiyatallah University of Medical Sciences, Tehran, Islamic Republic of Iran

7. Medicine, Quran and Hadith Research Center, Baqiyatallah University of Medical Sciences, Tehran, Iran

\begin{abstract}
Introduction: Evidence-based nursing and self-efficacy are significant factors behind quality care delivery in critical care units. Aim: This study aimed to assess the effects of an evidence-based nursing training workshop on critical care nurses' self-efficacy. Methods: This two-group pretest-posttest quasi-experimental study was undertaken in 2016 in two large-scale hospitals in Tehran, Iran. The participating nurses from one hospital were purposefully allocated to the intervention group and the other hospital's participants comprised the control group. A convenience sample of 45 nurses was selected from each hospital. For nurses in the intervention group, an evidence-based nursing training workshop was held in four two-hour sessions on two successive days, while the nurses in the control group received no specific evidence-based nursing training. Findings: After the intervention, these values increased to $51.1 \pm 2.49$ and $61.6 \pm 2.05$, respectively. The increase in the intervention group was statistically significant $(\mathrm{P}=0.001)$, while the increase in the control group was insignificant $(\mathrm{P}=0.06)$. Thus, the posttest mean score of self-efficacy in the intervention group was significantly greater than the control group. Conclusion: Evidence-based nursing training significantly improves the nurses' self-efficacy. Therefore, healthcare policy-makers and authorities are recommended to provide nurses with in-service and evidence-based nursing training programs.
\end{abstract}

Keywords: Self Efficacy, Evidence-Based Nursing, Critical Care, Iran.

\section{Introduction}

Patients in critical care units are often severely-ill and suffer from different problems associated with their vital organs. Moreover, complicated situations in critical care units can make clinical decision-making difficult. Therefore, critical care nurses need to be competent enough to deliver quality care to patients dealing with serious health problems (1). The competence of critical care nurses can play a significant role in restoring the health of critically-ill patients' health through providing superior care, using modern medical equipment, and group decision-making (2). The American Association of Critical Care Nurses developed the Synergy Model which holds that critical

*Corresponding Author:

\section{Abolfazl Rahimi}

$\mathrm{PhD}$ Assistant Professor, Health Research Center, Nursing Faculty, Baqiyatallah University of Medical Sciences, Tehran, Islamic Republic of Iran,

Medicine, Quran and Hadith Research Center, Baqiyatallah University of Medical Sciences,

Tehran, Iran

Email id: rahimi@bmsu.ac.ir care nurses need to have the eight characteristics of clinical judgement, advocacy and moral agency, caring practices, systems thinking, response to diversity, collaboration, clinical inquiry, and facilitation of learning. This model holds that patients' and families' characteristics can interact with and influence nurses' characteristics. Moreover, this model states that synergy occurs when the nurses' characteristics and competencies are in line with patients' needs and characteristics (3).

Apart from the constant scientific advancements, the unstable conditions of critically-ill patients require critical care nurses to use their technical skills, professional knowledge, and available evidence to diagnose the patients' problems and develop, implement, and evaluate care plans for managing the diagnosed problems (4). On the other hand, modern nursing highly values quality care delivery, care effectiveness, and patient-centered care. These requirements can be fulfilled through evidence-based nursing (EBN) and best clinical practice (5).

EBN includes four key steps, namely formulating the intended clinical scenario into an organized answerable question, searching literature to find relevant 
evidence for answering the question, critically evaluating the evidence for credibility and applicability, and using the results of evaluation in clinical practice (6). EBN is defined as a systematic process of decisionmaking for patient care based on the existing evidence which includes recent research findings, patients' preferences, and personal clinical experience (7). Studies show that nurses who adopt an evidence-based practice make wise decisions that are associated with lower healthcare costs, shorter hospital stay, greater satisfaction for patients and organizations, and greater organizational effectiveness.

The most important barriers to EBN are nurses' inability to use research evidence, their unfamiliarity with search strategies and scientific databases, and their incompetence in critical evaluation of the retrieved evidence (7). A study showed that a large number of American nurses did not use research findings, 76\% of them did not use CINAHL database, and $58 \%$ of them had never entered the Medline database (8). Another study reported that although nurses had positive attitudes toward EBN, $72.5 \%$ of them received their necessary data from their classmates and peers instead of referring to journals and textbooks, and only $24 \%$ of them sought answers to their questions in the CINAHL database (9).

One strategy for narrowing theory-practice gap is to shift teaching-learning towards EBN and to move towards self-effectiveness. In EBN, clinical problems are considered as ways for promoting the nurses' active involvement in learning. Therefore, EBN helps nurses acquire greater self-confidence and self-efficacy in learning (10).

Self-efficacy is defined as the degree of control an individual has over his/her life (11). It is closely related to the ability to perform the assigned tasks and is a link between knowledge and action (12). Therefore, it plays significant roles in helping individuals broaden their knowledge (13), improve their skills (14), and use their professional knowledge and skills in practice $(15,16)$. Moreover, it is a significant factor behind academic achievement and failure. A study showed that nursing students with higher self-efficacy had better academic performance compared with those who had lower selfefficacy. The study also showed that although low selfefficacy is not the only reason behind academic failure, it can significantly contribute to the ineffective use of the learned skills in practice (17).

Despite the wealth of studies into EBN and selfefficacy among nurses and nursing students, there is limited data about the effectiveness of EBN training in promoting self-efficacy in critical care units. This study aimed to assess the effects of an EBN training workshop on the self-efficacy of critical care nurses.

\section{Method}

This quasi-experimental study was undertaken in 2016. The population of the study constituted of all critical care nurses who worked in two large-scale hospitals in Tehran, Iran. The nurses of the hospital that afforded better availability of the facilities, as needed for the study intervention, was allocated as the intervention group and the nurses of the other hospital comprised the control group. A convenience sample of 45 critical care nurses was recruited from each hospital. With a Type I error of 0.01 and a power of 0.95 , and using the results of a previous study on self-efficacy (18), 41 nurses per group were estimated to be necessary (Figure 1). Yet, considering an attrition rate of $10 \%$, we decided to increase the sample size to 45 .

$$
n=\frac{\left(S_{1}^{2}+S_{2}^{2}\right)\left(Z_{1-\alpha / 2}+Z_{1-\beta}\right)^{2}}{\left(\mu_{1-} \mu_{2}\right)^{2}}=\frac{\left(1.16^{2}+1^{2}\right)(17.84)^{2}}{(4.25-1.16)^{2}}=33.5
$$

Figure 1. Sample size calculation

The selection criteria included Bachelor's or higher degrees in nursing, a clinical work experience of five years or more, no simultaneous employment in the critical care units of both hospitals, and a score of less than 70 for the self-efficacy questionnaire. The nurses who moved from critical care units to general hospital wards or those who withdrew from the study were excluded.

Two questionnaires were used for data collection. The first was a questionnaire on the nurses' demographic characteristics such as age, gender, educational status, work experience, marital status, and previous history of participation in EBN courses or workshops. The second was a seventeen-item Generalized Self-Efficacy Scale (GSE). This questionnaire includes four main domains, namely clinical (five items), theoretical (four items), motivational (four items), and organizational (four items). Item scoring is performed on a five-point scale from 1 ("Completely disagree") to 5 ("Completely agree"). Of course, items with negative wording (i.e. Items 1, 3, 8, 9, 13, and 15) are reversely scored. The lowest and the highest possible scores of GSE are 17 and 85, respectively. Shere et al. reported a Cronbach's alpha of 0.76 for the scale and approved its construct validity (19). A study also reported that the Cronbach's alpha of the Persian GSE was 0.83 (20).

The study intervention was the same as the intervention in an earlier study (21). Accordingly, a two -day theoretical and practical EBN training workshop was held for nurses in the intervention group. On the first day, nurses were taught for two hours about EBN, identification and formulation of a clinical problem or question, literature search, and critical appraisal of the retrieved documents. Pamphlets containing EBN training materials were also provided to nurses. In the second two-hour session on the first day, nurses were divided into nine five-person groups and were provided with a scenario about "prevention of pressure ulcers in critical care units." After that, they were required to formulate questions about the scenario through group discussion, choose search terms based on the formulated questions, and search the terms in scientific databases under the supervision of the first author. Each group provided a hard copy of their search results to us. At the end of the first day of workshop, the retrieved documents were critically appraised. On the second day, the groups worked in the same way as the first day, on a new scenario entitled "the newest treatments for 
pressure ulcer treatment in critical care units." The workshop was held in four two-hour sessions on two successive days. On the other hand, nurses in the control group received no specific EBN training. All participants completed GSE both before and after the intervention.

The SPSS software (v. 19.0) was employed to analyze the data via the independent-sample $t$, pairedsample $t$, chi-squared test, and Fisher exact test. The normality of all study variables was ensured via the Kolmogorov-Smirnov test.

This study has the approval of the Ethics Committee of a local medical university (with the code of A.J.9175.37). The study was conducted based on the principles of the Declaration of Helsinki. Accordingly, study aims were explained to the participants and they were given the right to voluntarily participate or withdraw from the study. We collected and analyzed the data honestly and offered the participants free access to study findings. Moreover, an EBN training session was held after the posttest for nurses in the control group.

\section{Findings}

This study was conducted on 90 nurses in two 45-person groups. The majority of nurses in the control and the intervention groups were female (51.1\% vs. $57.7 \%$ ), married $(53.3 \%$ vs. $57.7 \%)$, and held a Bachelor's degree (93\% vs. 95\%). The means of age in the control and intervention groups were $33.95 \pm 5.7$ and $34.2 \pm 5.6$, respectively. The work experience in critical care units in both groups ranged from five to 23 years. None of the participants had previously attended EBN courses. The results of the chi-squared, Fisher exact, and independent-sample $t$ tests revealed that the groups were not significantly different from each other in respect to participants' gender, marital status, educational status, age, and work experience $(\mathrm{P}<0.05$; Table 1).

Before the intervention, the mean scores of selfefficacy in the control and intervention groups were $48.90 \pm 2.65$ and $49.40 \pm 2.72$, respectively, denoting low self-efficacy in both groups. With respect to the pretest mean score of self-efficacy, it was not statistically significant between the two groups $(P=0.969)$. After the intervention, the mean score of self-efficacy in the control group insignificantly increased to $51.10 \pm 2.49$ $(\mathrm{P}=0.06)$, while in the intervention group, it significantly increased to $61.60 \pm 2.05(\mathrm{P}=0.0001)$. Consequently, the posttest mean score of self-efficacy in the intervention group was significantly greater than the control group $(\mathrm{P}=0.0001$; Table 2$)$.

\section{Discussion}

This study aimed to assess the effects of an EBN training workshop on the self-efficacy of critical care nurses. The low mean score of self-efficacy in both groups before the intervention highlights the necessity of EBN training for nurses in order to improve their self-efficacy. An earlier study also showed that paramedics had limited self-efficacy in airway management in emergency situations (22). Another study reported that nurses' managerial self-efficacy was less than the optimum level (23).

The results of this study also showed significant increase in the mean score of self-efficacy in the intervention group and no significant increase in the mean score of self-efficacy in the control group. These findings imply the effectiveness of the two-day EBN training workshop in improving nurses' self-efficacy. Previous studies reported the same finding. For instance, a study showed that an educational program significantly improved nurses' personal self-efficacy in all aspects of care delivery to cardiac patients. A twomonth follow-up in that study also showed that the effects of the program still persisted two months after the intervention (24). Another study also found that simulation training significantly improved self-efficacy for working in emergency situations among newlygraduated critical care nurses (25). Moreover, a qualitative study highlighted that evidence-based learning was associated with higher self-efficacy, greater problem-solving and thinking abilities, closer group interaction, greater self-confidence, and greater ability to link theory to practice (26). Similarly, another study reported that evidence-based training was more effective than conventional teaching methods in improving nursing students' self-efficacy (27). EBN and EBN training helps nurses reflect on clinical issues and problems and promotes experiential and discovery learning (28).

The most important issue in the area of EBN training is the quality of training programs. Most universities are currently trying to find and develop the best training approaches to promote effective learning capacities, clinical decision-making, self-confidence, and self-efficacy in personal knowledge advancement. Quality EBN improves not only the nurses' selfefficacy, but also patient satisfaction, professional identity, and care quality (29).

Individuals with high self-efficacy usually set higher goals for themselves, the attainment of which requires them to make more serious attempts and to use opportunities more effectively. Self-efficacy gives people a sense of competence. Such a sense can create positive beliefs and result in effective performance. Hence, self-efficacy is considered as one's belief in his/her own ability to solve problems. On the other hand, those with limited self-efficacy may think that the status quo is unchangeable and therefore, they may make no attempt or else allocate limited time to improve their situations or solve their problems. They also show limited endurance in the face of problems (30).

\section{Conclusion}

This study concludes that critical care nurses have problems in finding, appraising, and using the existing evidence in their practice. EBN training significantly improves nurses' self-efficacy and their professional knowledge. Therefore, healthcare policymakers and authorities can improve nurses' selfefficacy and care quality through providing them with in-service EBN training programs. 
Figure 1.The flow diagram of the study

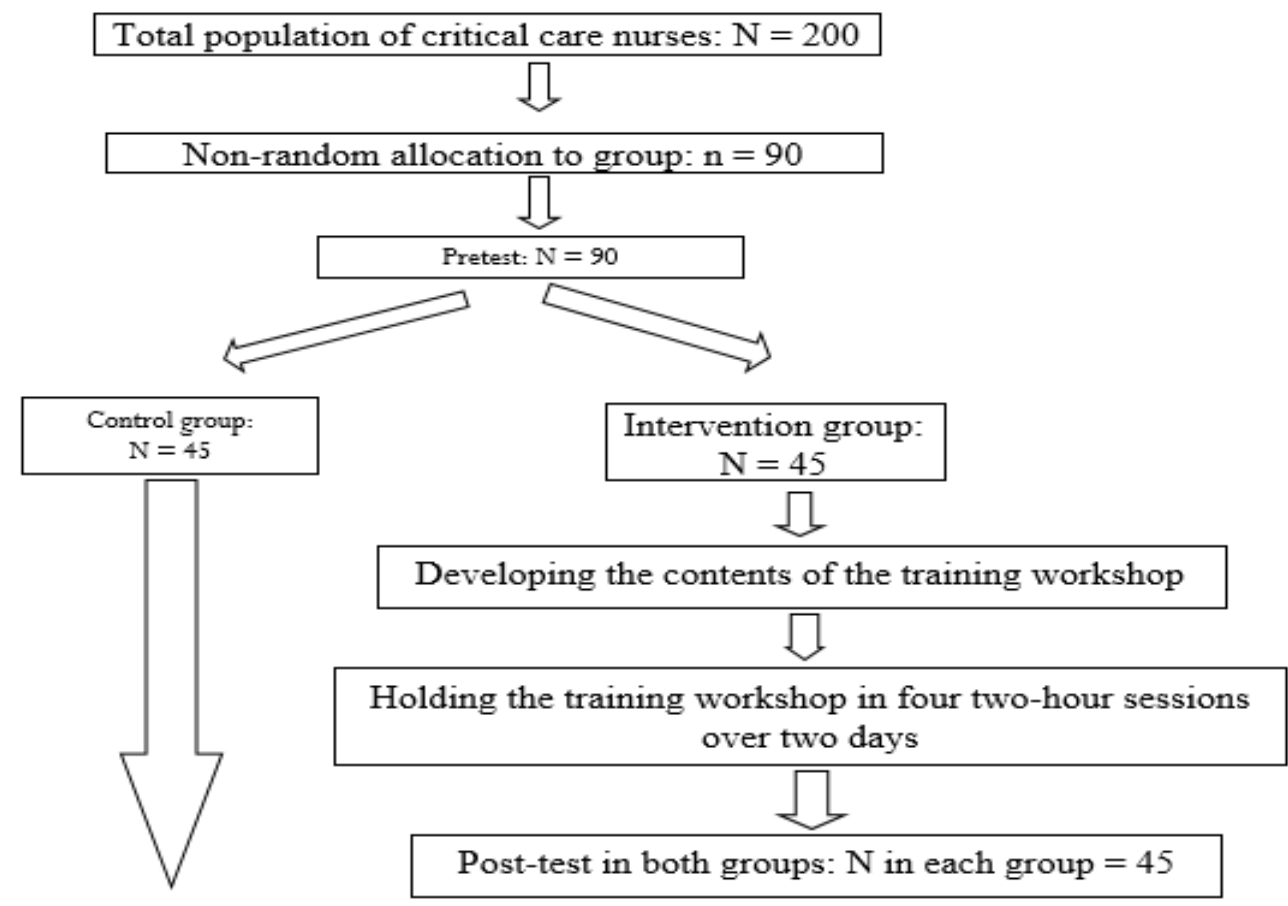

Table 1.Participants' demographic characteristics

\begin{tabular}{|c|c|c|c|c|}
\hline \multirow{2}{*}{\multicolumn{2}{|c|}{$\begin{array}{ll} & \text { Groups } \\
\text { Characteristics } & \end{array}$}} & \multirow{2}{*}{$\begin{array}{l}\text { Intervention } \\
\mathrm{N}(\%)\end{array}$} & \multirow{2}{*}{$\begin{array}{l}\text { Control } \\
\mathrm{N}(\%)\end{array}$} & \multirow{2}{*}{$\begin{array}{l}\text { P value(chi-squared or independent } \\
\text {-sample t tests) }\end{array}$} \\
\hline & & & & \\
\hline \multirow[t]{2}{*}{ Gender } & Female & $26(57.7)$ & $23(51.1)$ & \multirow{2}{*}{$\begin{array}{l}\chi^{2}=0.403 ; \mathrm{df}=1 \\
P=0.525\end{array}$} \\
\hline & Male & $19(42.2)$ & $22(48.8)$ & \\
\hline \multirow[t]{2}{*}{ Marital status } & Single & $19(42.2)$ & $21(46.6)$ & \multirow{2}{*}{$\begin{array}{l}\chi^{2}=0.180 ; \mathrm{df}=1 \\
\mathrm{P}=0.671\end{array}$} \\
\hline & Married & $26(57.7)$ & $24(53.3)$ & \\
\hline \multirow[t]{2}{*}{ Educational status } & Bachelor's & $43(95.5)$ & $42(93.3)$ & \multirow{2}{*}{$\begin{array}{l}\chi^{2}=0.212 ; \mathrm{df}=1 \\
\mathrm{P}=0.645\end{array}$} \\
\hline & Master's & $2(4.4)$ & $3(6.6)$ & \\
\hline & & Mean \pm SD & Mean \pm SD & \\
\hline \multicolumn{2}{|l|}{ Age (Years) } & $34.2 \pm 5.6$ & $33.95 \pm 5.7$ & $\mathrm{t}=0.204 ; \mathrm{P}=0.839$ \\
\hline \multicolumn{2}{|c|}{ Work experience (Years) } & $4.9 \pm 3.6$ & $10.2 \pm 4.6$ & $\mathrm{t}=0.920 ; \mathrm{P}=0.360$ \\
\hline
\end{tabular}

Table 2.Within- and between-group comparisons in terms of self-efficacy

\begin{tabular}{|c|c|c|c|}
\hline \multirow{2}{*}{$\begin{array}{lc}\text { Group } & \text { Time } \\
\end{array}$} & Before & After & \multirow{2}{*}{$\begin{array}{c}\text { P value } \\
\text { (Paired-sample } t \text { test) }\end{array}$} \\
\hline & $\operatorname{Mean} \pm$ SD & $\operatorname{Mean} \pm$ SD & \\
\hline Control & $48.90 \pm 2.56$ & $51.10 \pm 2.49$ & $\begin{array}{c}t=3.16 \\
d f=44 \\
p<0.06\end{array}$ \\
\hline Intervention & $49.4 \pm 2.72$ & $61.6 \pm 2.05$ & $\begin{array}{c}\mathrm{t}=23.25 \\
\mathrm{df}=44 \\
\mathrm{p}=0.001\end{array}$ \\
\hline $\begin{array}{l}\mathrm{P} \text { value } \\
\text { (Independent-sample } t \text { test) }\end{array}$ & $\begin{array}{c}\mathrm{t}=0.29 \\
\mathrm{df}=88 \\
\mathrm{p}<0.969\end{array}$ & $\begin{array}{c}\mathrm{t}=29.61 \\
\mathrm{df}=88 \\
\mathrm{p}=0.001\end{array}$ & - \\
\hline
\end{tabular}




\section{References}

1. Nezamzadeh M, Khademolhosseini S.M , Ebadi A, Mokhtari Nouri J, Quality of nursing evidence-based guidelines from the nurses' view, Crit Care Nurs J. 2011; 4(1):e7084.

2. Tofighi S, Meskarpour Amiri M, Ameriuon A, Naseri H, Equity in distribution of intensive care beds in Iran with Gini coefficient and Lorenz curve approach. Yafteh. 2011; 12(2):75-83.

3. Kerfoot K, Lavandero R, Cox M, Triola N, Pacini C, Hanson M, Conceptual models and the nursing organization: Implementing the AACN Synergy Model for patient care $^{\mathrm{TM}}$. Nurse Leader. 2006;4 (4):20-26.

4. Adib Hagbaghery M, Salsali M, Ahmadi F, A qualitrative study of Iranian nurses understanding and experience of peressional power. Human resource Healh. 2004;2(9):27-34.

5. Goldsmith S.B, Principles of Health Care Management: Foundations For A Changing Health Care System. Jones \& Bartlett Learning. 2nd ed. 2009

6. Kermanshahi S, Parvinian A.M, Barriers to Implementation of Evidence-Based Care: Viewpoints of Nursing Staff. Iranian Journal of Medical Education. 2012; 12 (2) :84-92.

7. Sackett D, Straus S, Richardson W, Rosenberg W, Haynes R, Evidence-Based Medicine. How toprac tice and Teach EBM. 2 nd ed Edinburgh: Churchill Livingston. 2000.

8. Corder S, Teaching Evidence-Based Practice: Application of the Ace Star Model in an Undergraduate Nursing Curriculum. Proceeding of Sixth annual Summer institute on evidence-based practice. 2007;23(2):25-2.

9. Thiel L, Ghosh Y, Determining Registered Nurses' Readiness for Evidence Based Practice. Worldviews on Evidence Based Nursing. 2008;5(4): 182-92.

10. Dicenso A, Cullum N, Ciliska D, Implementing evidence-based nursing: some misconceptions. Evidence Based Nursing. 1998;1(2): 38-9.

11. Bandura A, Self-efficacy mechanism in human agency. American psychologist. 1982;37(2): 122-47.

12. Zimmermon B.J, Self-Efficacy:An Essential Motive to Learn. Contemp Educ Psycol. 2000;25(1): 82-91.

13. Pajares F, Self-efficacy beliefs in academic setting. Rev Edu Res 1996;66(4):24-6.

14. Fereday J, Muir-Cochrane E, The role of performance feedback in the self-assessment of competence: a research study with nursing clinicians. Collegian 2006;13(1):5-10.

15. Rahimi A, Ahmadi F, The obstacles and improvingstrategies of clinical education from the viewpoints of clinical instructors in Tehran's Nursing Schools. Iran J Med Educ. 2005;5(2):73-80.

16. Ozturk C, Muslu GK, Dicle A, A comparisonof problem based and traditional education on nursing students' critical thinking dispositions. Nurse Educ Today. 2008;28(5): 627-32

17. Harvey V, McMurray N, Self-efficacy: ameans of identifying problems in nursing education and career progress. Int J Nurs Stud. 1994;31(5): 471-85.

18. Heidarzadeh A, Azizzade forouzi A, kazemi M, Jahani Y, The Effect of Computer Simulation and Mannequin on Nursing Students' Perception of Selfefficacy in Cardiopulmonary Resuscitation. . Iranian Journal of Medical Education. 2014;14(10):876-885.

19. Sherer M, Maddux J, Mercandante B, Prentice-Dunn S, Jacobs B, Rogers R.W, The selfefficacy scales: Costruction and validation. Psychological Reports. 1982;51(2(:671-663.

20. Narimani M, Salehi M, Kazemi, The Effectiveness of Dialectical Behavior Therapy on Stress Reduction and Increasing Self-Efficacy among Nurses. Journal of Health and Care. 2016;17(4):270-80.

21. Taheri H, Mirmohammad Sadeghi M, Adibi 1, Ashourioun V, Sadeghizadeh A, The Effect of an Evidence Based Medicine Workshop on Undergraduate Medical Students' Skills in Applying EBM. Iranian Journal of Medical Education. 2006;6 (2):70-79.

22. Youngquist S.T, Henderson D.P, Gausche-Hill M, Goodrich S.M, Poore P.D, Lewis R.J, Paramedic self-efficacy and skill retention in pediatric airway management. Academic Emergency Medicine 2008;15(12): 1295-1303.

23. Purfarzad Z, Farahani M, Vanaki Z, Ghamarizare Z, Ghorbani M, Assessment charge nurses' managerial self-effcacy. Quarterly Journal of Nursing Management. 2014;2(4): 8-16.

24. Baas L.S, Conway G, Dietrich D, Selff-efficacy of nurses caring for patients with heart failure. Journal of Cardiac Failure. 2003;9(5): 95-102.

25. Chang S, Kwon E, Kwon Y.O, Kwon H.K, The effects of simulation training for newgraduate Critical care nurses on knowledge, self-efficacyand performance ability of emergency situations at intensive care unit. Journal of Korean Academic of Adult Nursing. 2010;22(4): 375-383.

26. Abedini Z, Ahmari Tehran H, Khorami Rad A, Heidarpour A, Nursing Students' Experiences on Evidence-Based Learning inClinical Setting: A Qualitative Study. Iranian Journal of Medical Education. 2011;11(8): 864-72.

27. Habibzadeh H, Khajeali N, Khalkhali H.R, Mohammadpour Y, Effect of Evidence-Based Education on Nursing Students' Self-Efficacy. Strides Dev Med Educ. 2015; 11(4):500-507.

28. Moattari M, Abedi H, Nursing Students' Experiences in Reflective Thinking: A Qualitative Study. Iranian Journal of Medical Education. 2008;8 (1): 101-12.

29. Green M.L, EvidenceBased Medicine Training in Internal Medicine Residency Programs. J Gen Intern Med. 2000;15(2): 129-33.

30. Rostami R, Shahmohamadi K, Ghaedi G, Besharat M.A, Akbari Zardkhaneh S, Nosratabadi M, Relations Among Self-efficacy, Emotional Intelligence and Perceived Social Support in University Students. Horizon Med Sci.2010;16 (3):46-54 